\title{
An Aerial Radiological Survey of Selected Areas of the City of North Las Vegas
}

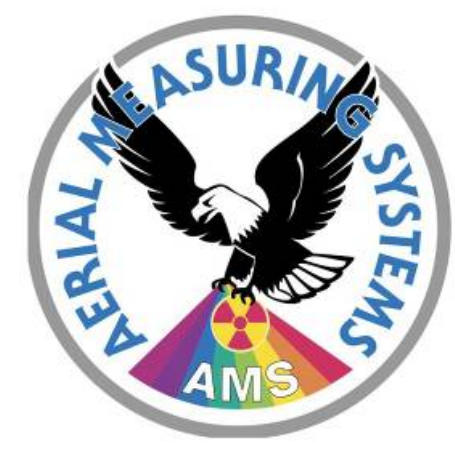

Piotr Wasiolek

Project Scientist

Remote Sensing Laboratory-Nellis

Survey Dates:

December 11-12, 2007 (Phase 1)

February 28, 2008 (Phase 2)

March 19-20, 2008 (Phase 3)

This document is UNCLASSIFIED

Reviewed by

Angela Anderson, May 30, 2008

Derivative Classifier 


\section{DISCLAIMER}

This report was prepared as an account of work sponsored by an agency of the U.S. Government. Neither the U.S. Government nor any agency thereof, nor any of their employees, nor any of their contractors, subcontractors or their employees, makes any warranty or representation, express or implied, or assumes any legal liability or responsibility for the accuracy, completeness, or usefulness of any information, apparatus, product, or process disclosed, or represents that its use would not infringe privately owned rights. Reference herein to any specific commercial product, process, or service by trade name, trademark, manufacturer, or otherwise, does not necessarily constitute or imply its endorsement, recommendation, or favoring by the U.S. Government or any agency thereof. The views and opinions of authors expressed herein do not necessarily state or reflect those of the U.S. Government or any agency thereof. 


\section{Table of Contents}

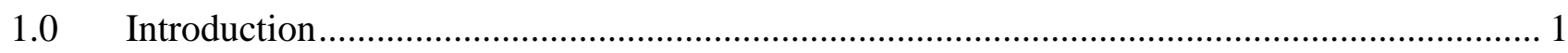

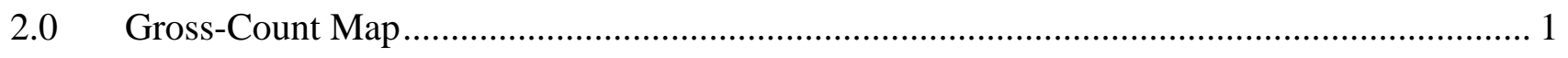

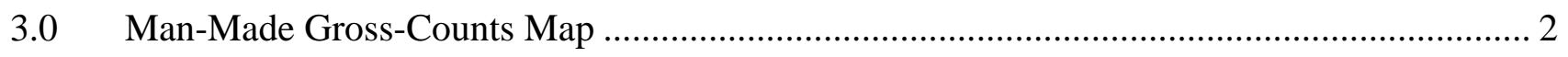

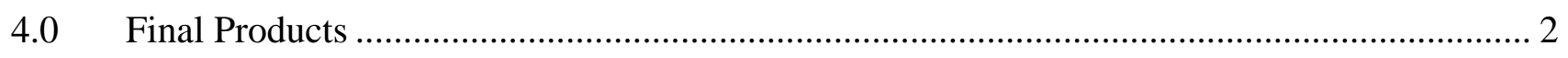

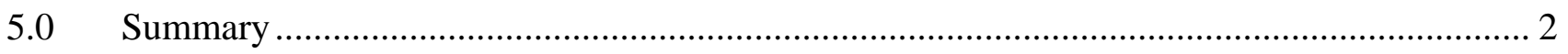

\section{Figures}

Figure 1. Helicopter flight lines over Las Vegas Motor Speedway .................................................. 3

Figure 2. Helicopter flight lines over Downtown North Las Vegas ............................................... 4

Figure 3. Helicopter flight lines over I-15 Industrial Corridor........................................................... 5

Figure 4. Helicopter flight lines over site of future UNLV Campus................................................. 6

Figure 5. Gross-counts derived exposure rate map around Las Vegas MotorSpeedway .................... 7

Figure 6. Gross-counts derived exposure rate map around downtown of City ofNorth Las Vegas . 8

Figure 7. Gross-counts derived exposure rate map around I-15 Industrial Corridor ......................... 9

Figure 8. Gross-counts derived exposure rate map around future UNLV Campus .......................... 10

Figure 9. Man-made counts map around Las Vegas Motor Speedway .............................................. 11

Figure10. Man-made counts map around downtown of City of North Las Vegas ........................... 12

Figure11. Man-made counts map around I-15 Industrial Corridor .................................................... 13

Figure 12. Man-Made counts map around future UNLV Campus...................................................... 14

Figure 13. Terrestrial gamma exposure rate in the U.S.A............................................................. 15 


\subsection{Introduction}

As part of the proficiency training for the Radiological Mapping mission of the Aerial Measuring System (AMS), a survey team from the Remote Sensing Laboratory-Nellis (RSL-Nellis) conducted an aerial radiological survey of selected areas of the city of North Las Vegas for the purpose of mapping natural radiation background and locating any man-made radioactive sources. Survey areas were selected in collaboration with the City Manager's office and included four separate areas:

1) Las Vegas Motor Speedway (10.6 square miles)

2) North Las Vegas Downtown Area (9.2 square miles)

3) I-15 Industrial Corridor (7.4 square miles)

4) Future site of University of Nevada Las Vegas campus (17.4 square miles)

The survey was conducted in three phases: Phase 1 on December 11-12, 2007 (Areas 1 and 2), Phase 2 on February 28, 2008 (Area 3), and Phase 3 on March 19, 2008 (Area 4). The total completed survey covered a total of 44.6 square miles. The flight lines (without the turns) over the surveyed areas are presented in Figures 1, 2, 3, and 4. A total of eight 2.5-hour-long flights were performed at an altitude of $150 \mathrm{ft}$ above ground level (AGL) with 300 feet of flight-line spacing. Water line and test line flights were conducted over the Lake Mead and Government Wash areas to ensure quality control of the data.

The data were collected by the AMS data acquisition system (REDAR V) using an array of twelve 2" x 4" x 16" sodium iodide (NaI) detectors flown on-board a twin-engine Bell 412 helicopter. Data, in the form of gamma energy spectra, were collected continually (every second) over the course of the survey and were geo-referenced using a differential Global Positioning System. Collection of spectral data allows the system to distinguish between ordinary fluctuations in natural background radiation levels and the signature produced by man-made radioisotopes. Spectral data can also be used to identify specific radioactive isotopes.

As a courtesy service, with the approval of the U.S. Department of Energy, National Nuclear Security Administration, Nevada Site Office, RSL-Nellis is providing this summary to the office of the Mayor of the City of North Las Vegas along with the gross-count-based exposure rate and manmade count contour maps and GIS shape files in electronic format on a compact disk.

\subsection{Gross-Count Map}

The exposure-rate maps are derived from the gross-count data that represent total counts per second detected in the twelve 2" x 4" x 16" NaI detectors. The gross count is based on the integration of total count rates of the spectra between 30 and 3,030 keV. The gross counts include all natural background and man-made radioisotopes. Terrestrial and cosmic radiations are the largest contributors to the natural background. In general, terrestrial background will vary with geological formation and changes in the ground coverage around the area. This variation in the gross count should not be considered as evidence of the presence of man-made radioisotopes. The gross counts expressed as an exposure rate map will, however, provide information pertaining to the total radiation levels of the area and fluctuations of the natural background levels. 
The gross-count data were converted to exposure-rate data using the AMS nominal conversion coefficient derived with the ground-truth measurement data using the following equation:

where:

$$
A_{X}=2246 e^{-z f}=1714.6\left[\frac{\text { counts } / \mathrm{sec}}{\mu R / h r}\right],
$$

$A_{X}=$ counts-exposure rate conversion coefficient in (counts $\left./ \mathrm{sec}\right) /(\mu \mathrm{R} / \mathrm{hr}$ )

$2246=$ counts-exposure rate conversion factor at $3 \mathrm{ft}$ derived from ground truth measurements over the test line $=2246$ (counts $/ \mathrm{sec}) /(\mu \mathrm{R} / \mathrm{hr})$

$z \quad=$ flight altitude of $150 \mathrm{ft}$ AGL

$f=$ linear air absorption coefficient derived from the altitude spiral of $0.0018 \mathrm{ft}^{-1}$

Figures 5, 6, 7, and 8 illustrate the exposure rates expressed as color contours around the Las Vegas Motor Speedway (LVMS), downtown North Las Vegas, the I-15 Industrial Corridor, and the future campus of University of Nevada, Las Vegas (UNLV). Each color represents exposure rates derived from total gross counts per second from the twelve detectors. The gross-count derived exposure rate map shows variations of the natural background levels caused by different concentrations of natural radioactive elements in surface soils, building and construction materials, radon, and cosmic radiation. Observed background variations were typical for local geology and consistent with previous data.

\subsection{Man-Made Gross-Count Map}

The man-made gross-count map is the fraction of the gross counts that are directly attributable to gamma radiation from man-made radioisotopes. The man-made gross count can be determined by subtracting natural background contributions (terrestrial and cosmic gamma radiation) from the gross count.

Figures 9, 10, 11, and 12 show the man-made gross-count maps of the surveyed areas. The obtained results do not show the presence of any radioactivity that cannot be attributed to natural background.

\subsection{Final Products}

RSL-Nellis final map products include paper and electronic (pdf format) contour maps of grosscount derived exposure rates and man-made gross-counts of the surveyed areas. In addition, a CD with the GIS shape files in ESRI ArcMap 9.2 format, images of maps in Adobe pdf format, and some aerial photographs of the surveyed areas are being provided.

\subsection{Summary}

The radiation background survey carried out over the selected areas of the city of North Las Vegas shows typical variations in the natural background radiation expressed as exposure rates. The measured values varied from 0 to $10 \mu \mathrm{R} / \mathrm{h}$ and 0 to $6.5 \mu \mathrm{R} / \mathrm{h}$ for downtown North Las Vegas and the LVMS, respectively. For comparison, Figure 13 shows the levels of the terrestrial natural background levels across the United States covering the same range of values as measured during this survey. During the time this current survey was conducted, no man-made radiation sources were detected. 


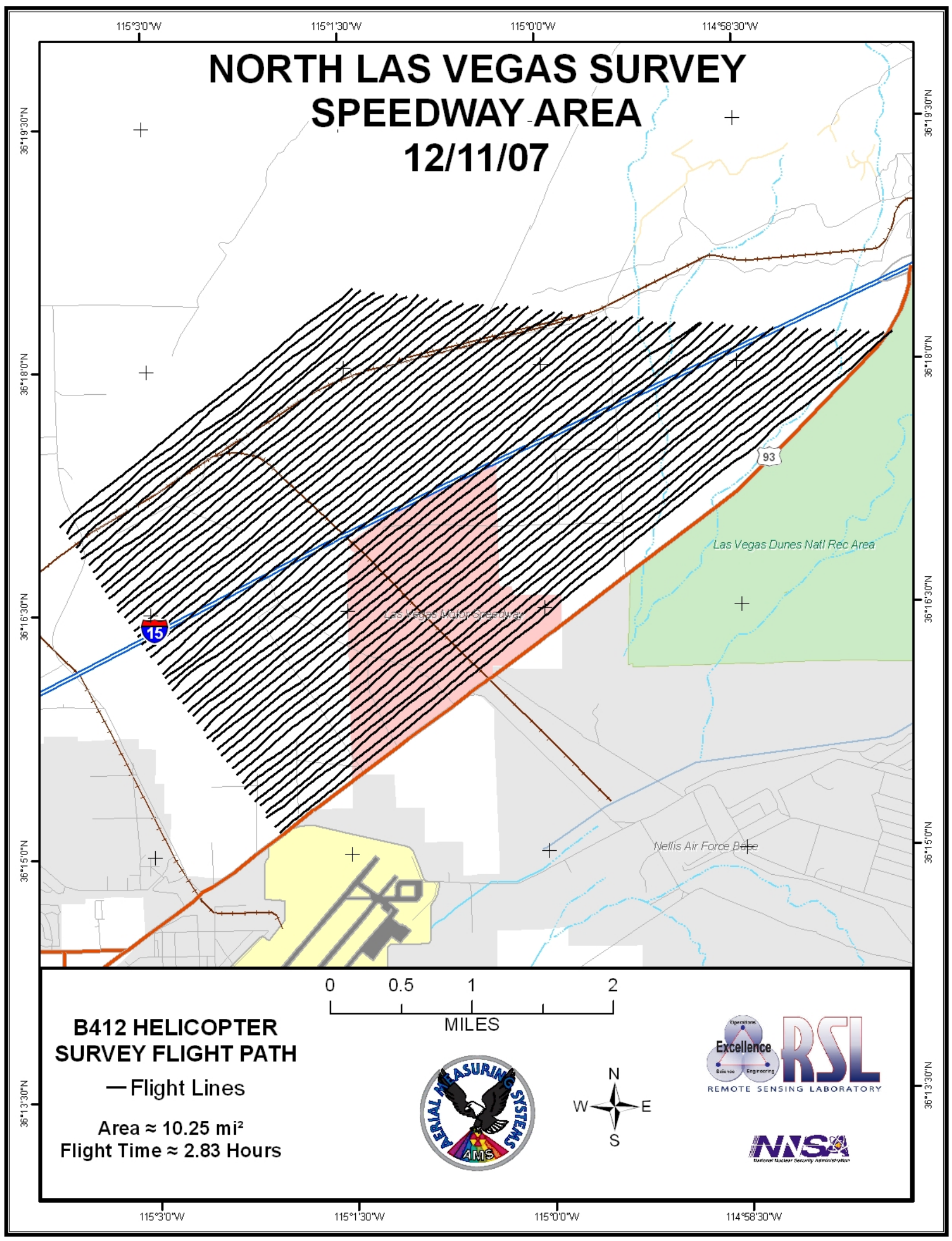

Figure 1. Helicopter flight lines over Las Vegas Motor Speedway. 


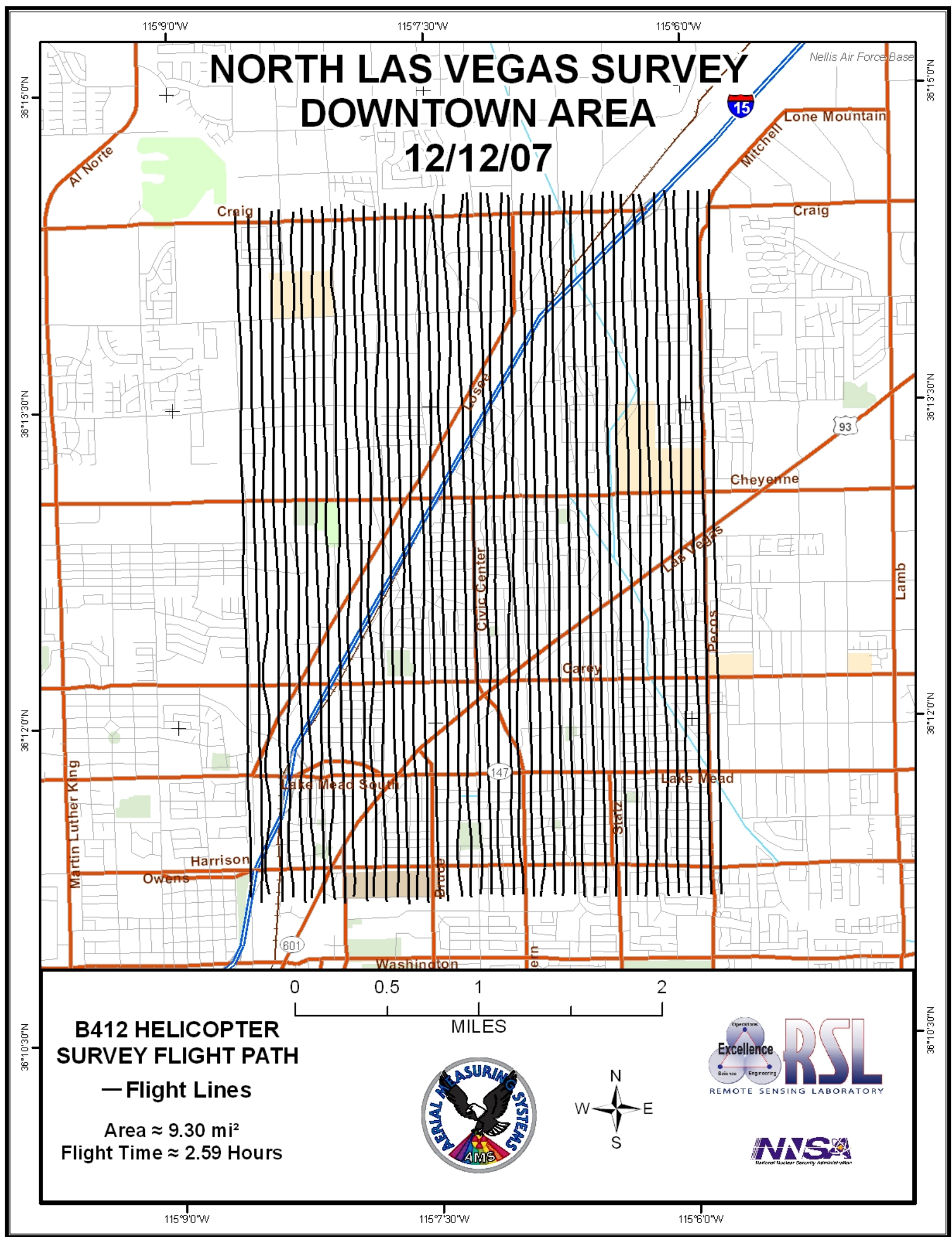

Figure 2. Helicopter flight lines over Downtown North Las Vegas. 




Figure 3. Helicopter flight lines over I-15 Industrial Corridor. 


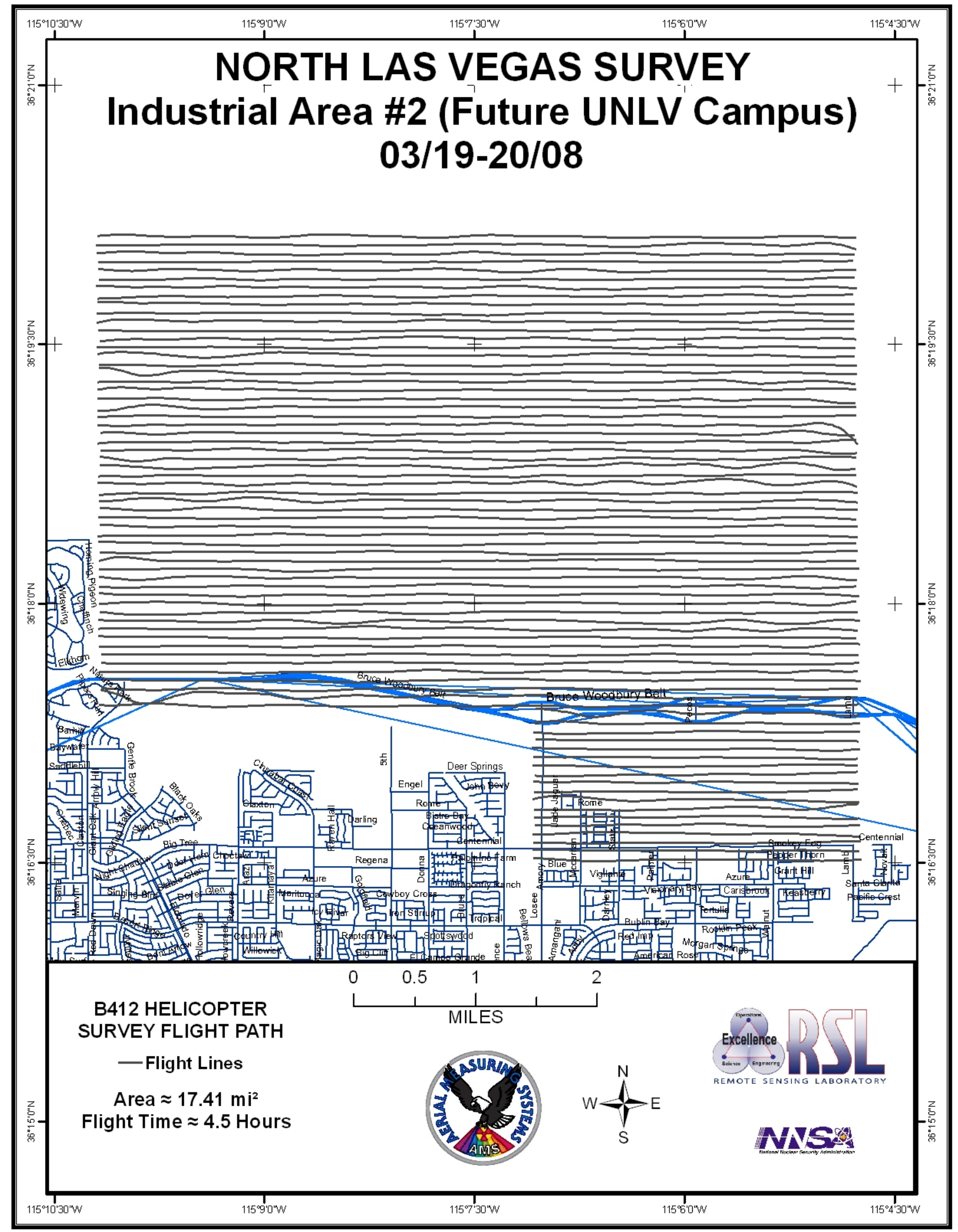

Figure 4. Helicopter flight lines over site of future UNLV Campus. 


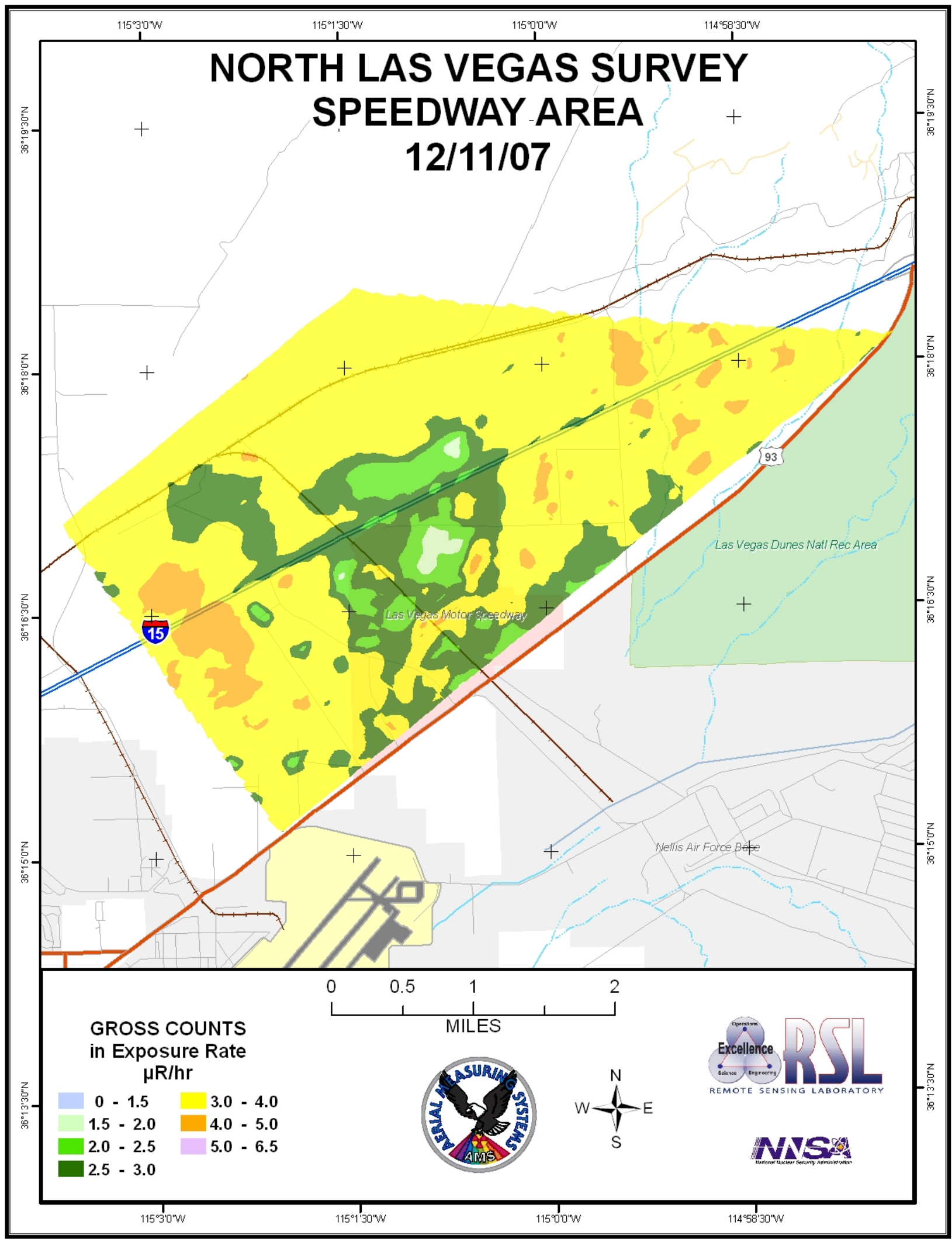

Figure 5. Gross-counts derived exposure rate map around Las Vegas Motor Speedway. 


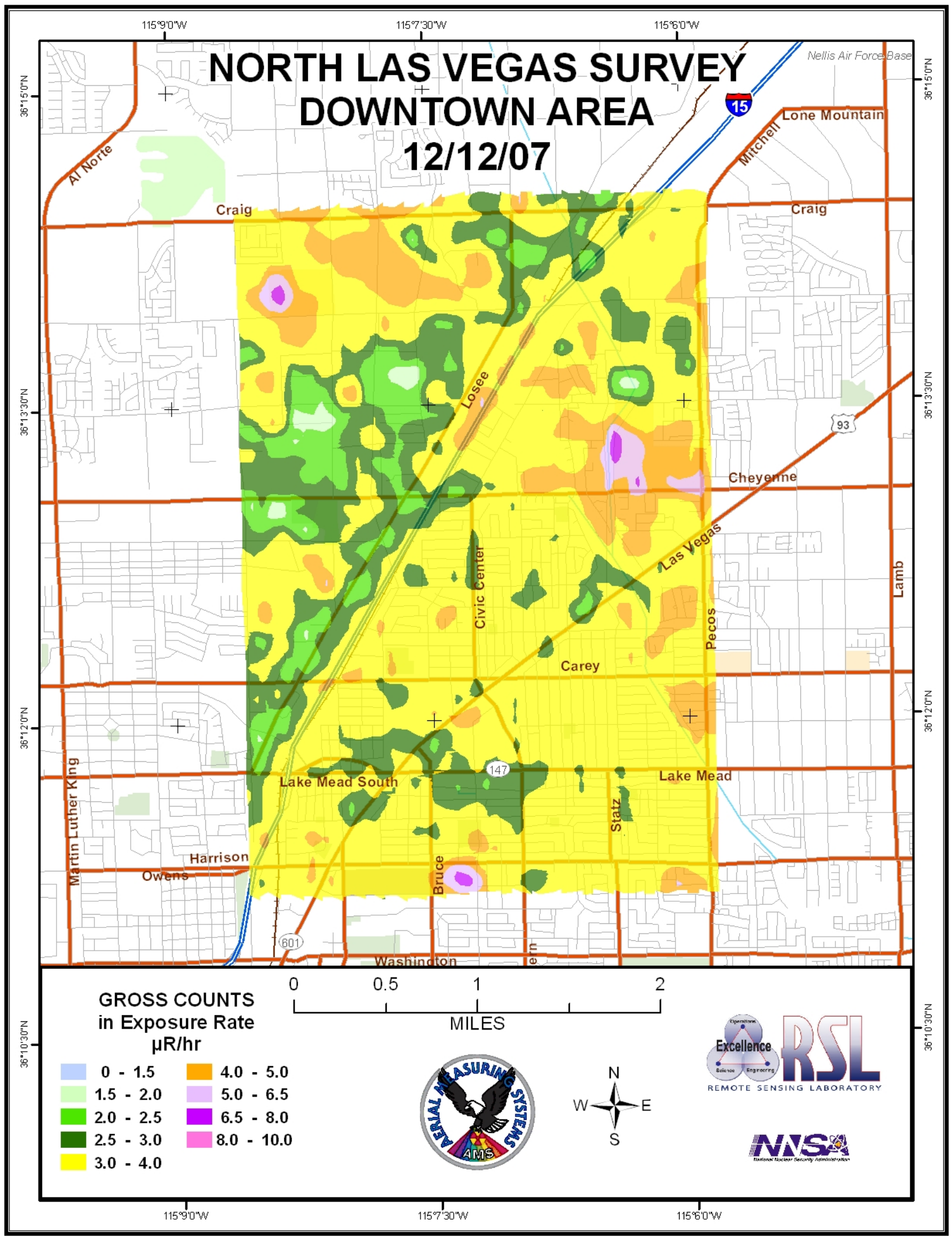

Figure 6. Gross-counts derived exposure rate map around downtown of City of North Las Vegas. 


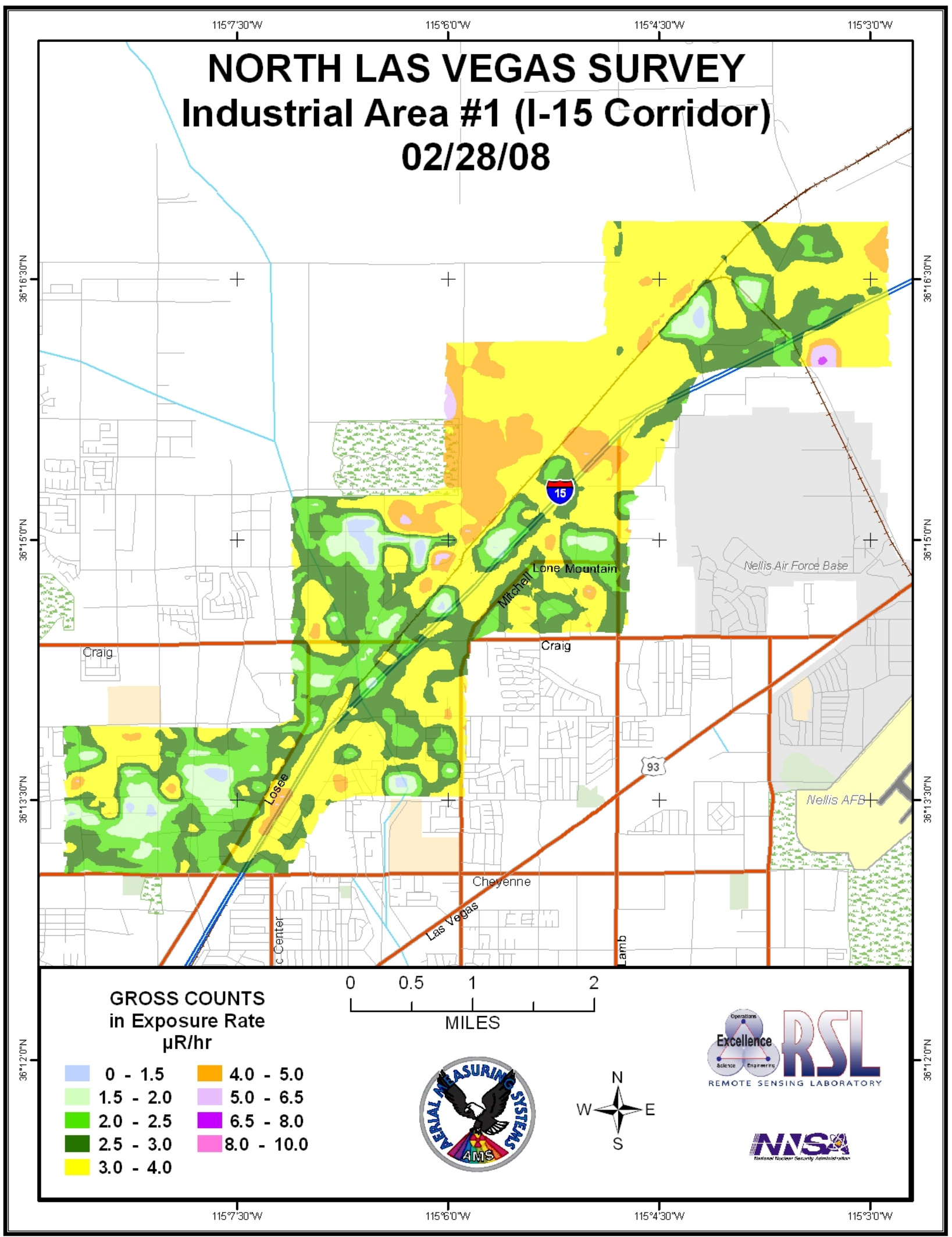

Figure 7. Gross-counts derived exposure rate map around I-15 Industrial Corridor. 


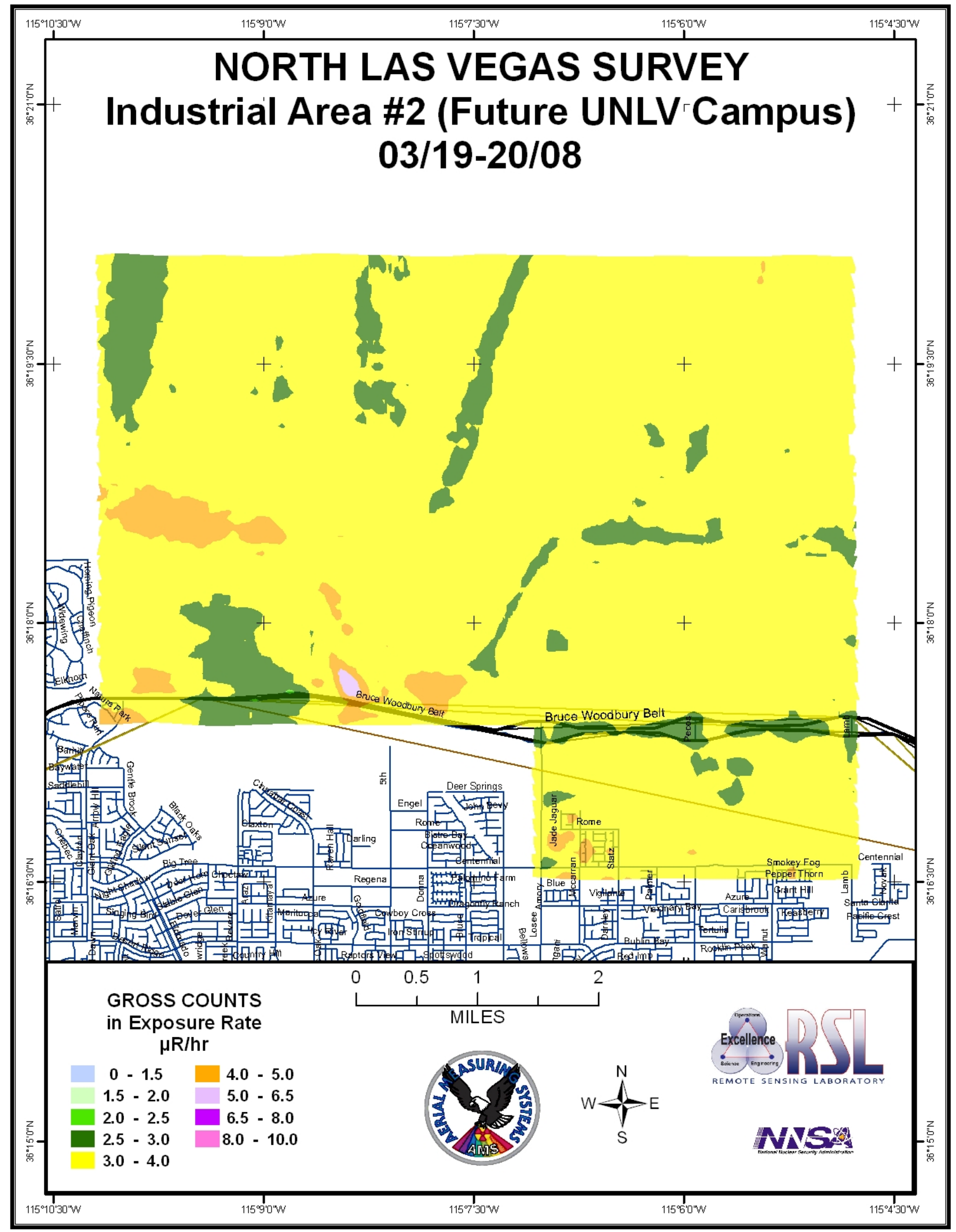

Figure 8. Gross-counts derived exposure rate map around future UNLV Campus. 


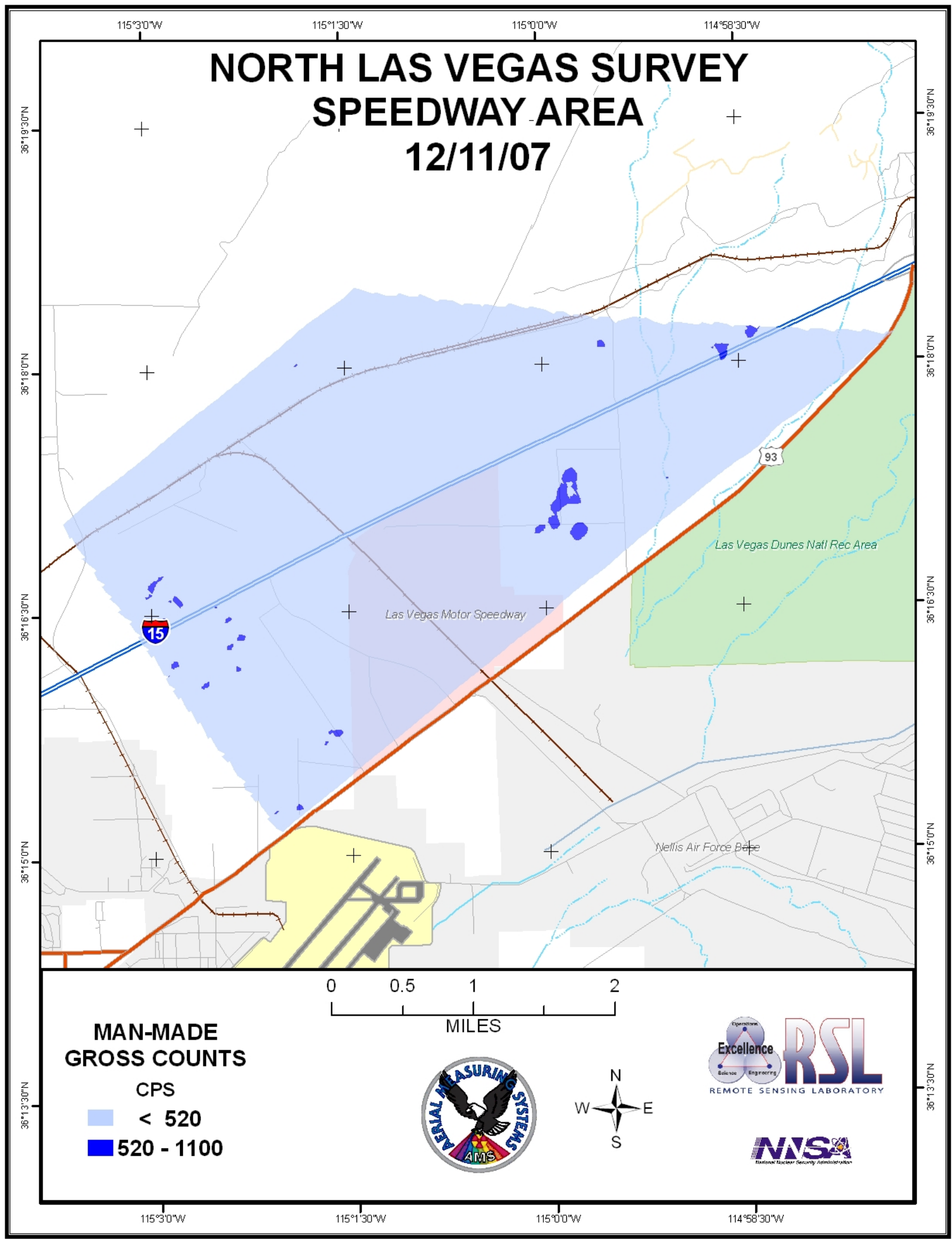

Figure 9. Man-made counts map around Las Vegas Motor Speedway. 


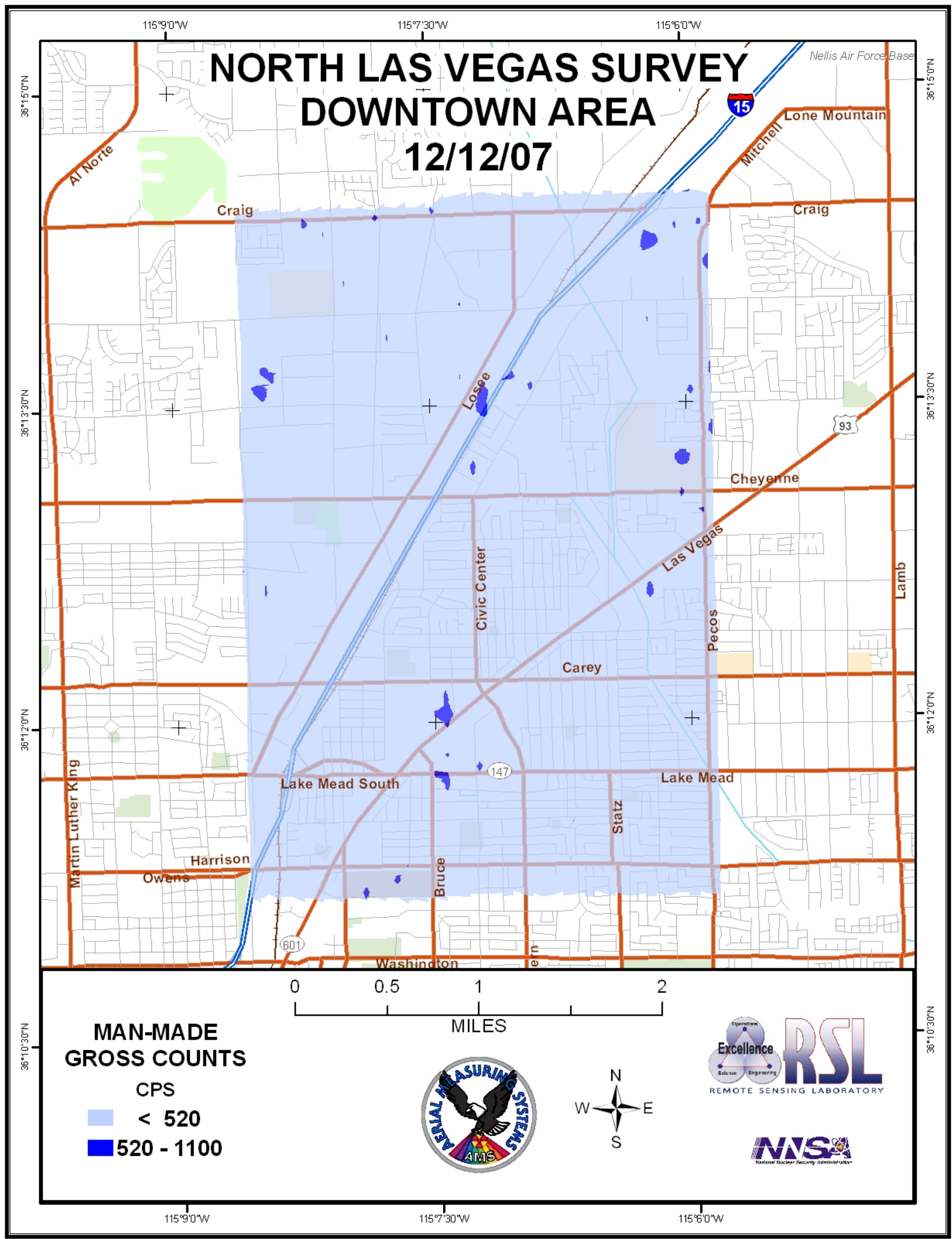

Figure10. Man-made counts map around downtown of City of North Las Vegas. 


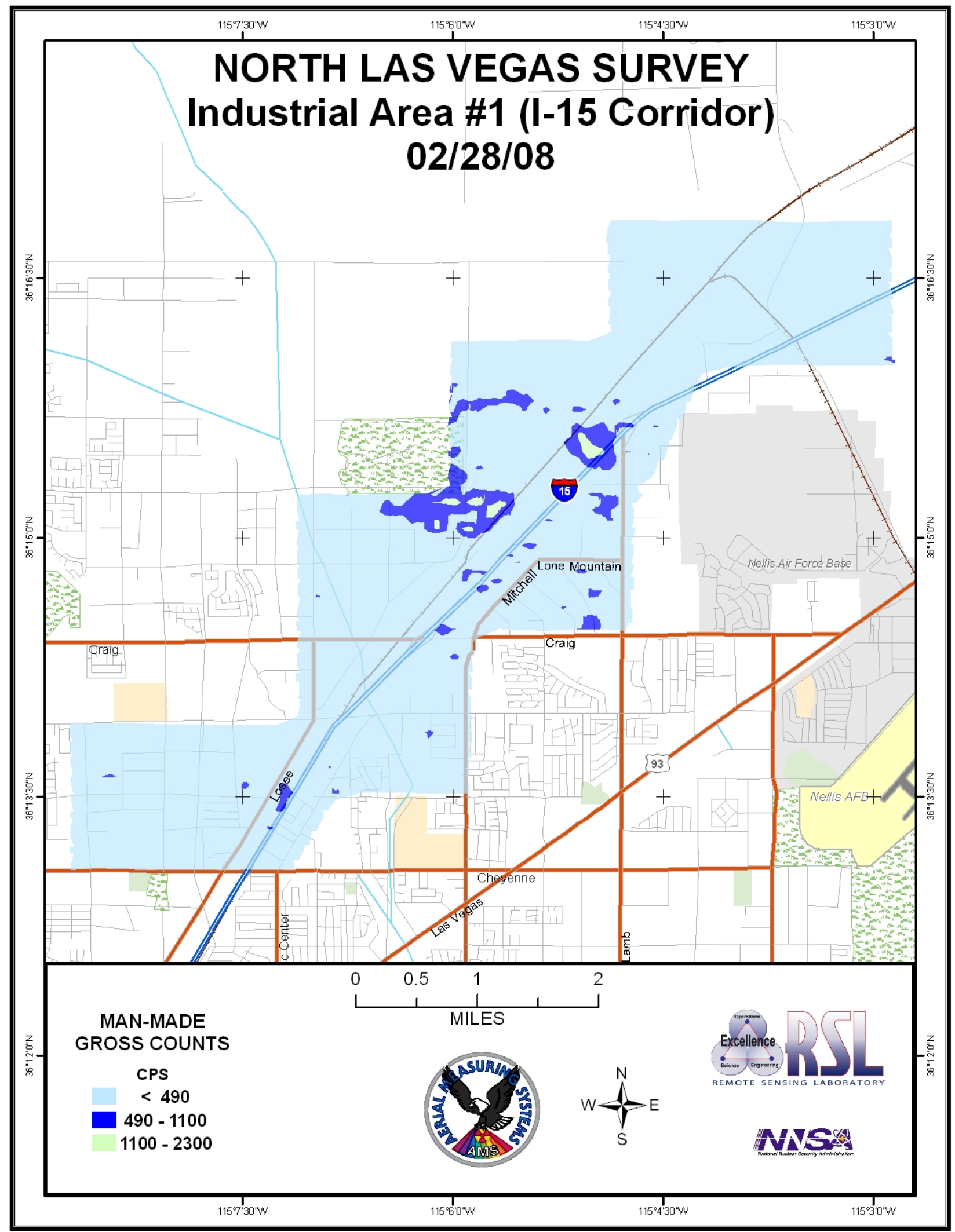

Figure11. Man-made counts map around l-15 Industrial Corridor. 


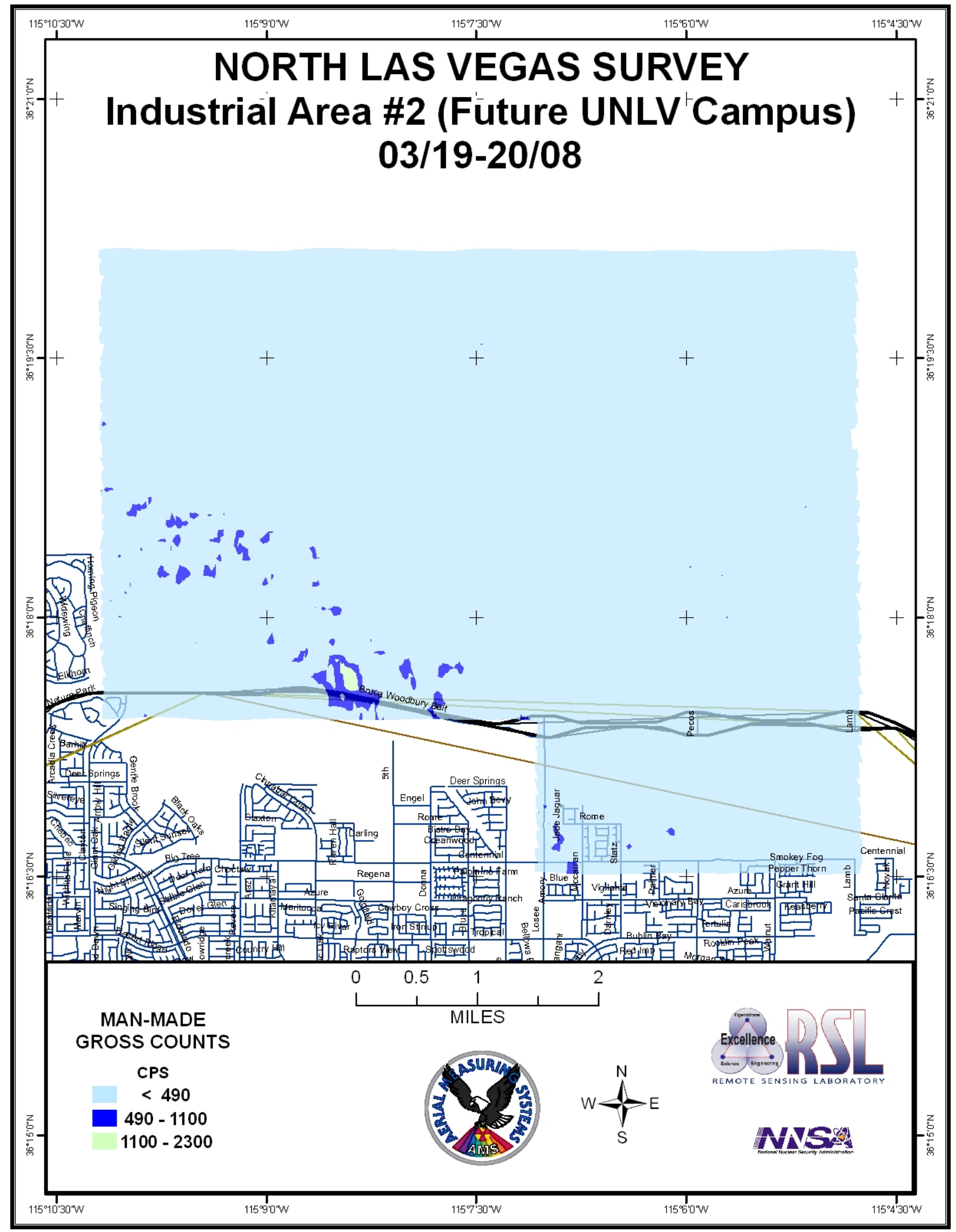

Figure 12. Man-Made counts map around future UNLV Campus. 


\section{Terrestrial Gamma-Ray Exposure at $1 \mathrm{~m}$ above ground}

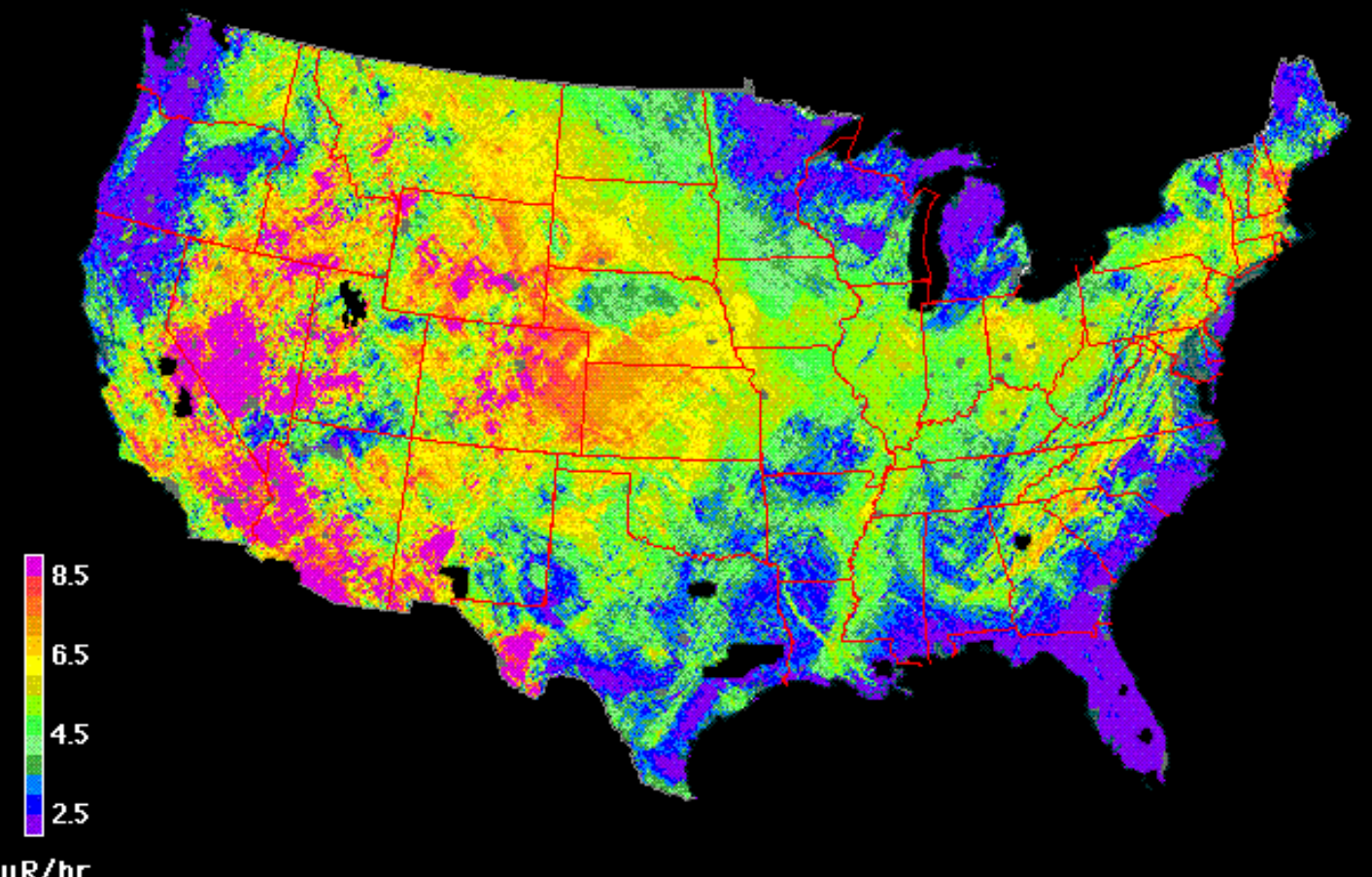

Source of data: U.S. Geological Survey Digital Data Series DDS-9, 1993

Figure 13. Terrestrial gamma exposure rate in the USA. 